\title{
Analytical Analysis and Field Test Investigation of Consolidation for CCSG Pile Composite Foundation in Soft Clay
}

\author{
Jin Yu, ${ }^{1}$ Yanyan Cai, ${ }^{1}$ Zhibo Qi, ${ }^{1}$ Yunfei Guan, ${ }^{2}$ Shiyu Liu, ${ }^{1}$ and Bingxiong Tu${ }^{1}$ \\ ${ }^{1}$ Geotechnical Engineering Institute, Huaqiao University, Xiamen 361021, China \\ ${ }^{2}$ Geotechnical Engineering Department, Nanjing Hydraulic Research Institute, Nanjing, Jiangsu 210024, China \\ Correspondence should be addressed to Jin Yu; bugyu0717@163.com
}

Received 6 June 2013; Revised 25 August 2013; Accepted 6 September 2013

Academic Editor: Fayun Liang

Copyright (c) 2013 Jin Yu et al. This is an open access article distributed under the Creative Commons Attribution License, which permits unrestricted use, distribution, and reproduction in any medium, provided the original work is properly cited.

\begin{abstract}
Low-grade concrete-cored sand-gravel (CCSG) pile composite foundation is a new kind of composite foundation for thick and soft clay ground treatment. An analytical solution was derived for calculating the consolidation process of this composite foundation by considering coefficients of horizontal permeability in smear zone, the radial flow within the sand-gravel shell, and the impervious property of concrete-cored pile. The results show that Terzaghi's one-dimensional consolidation solution and the consolidation analytical solution of ordinary composite foundation were special cases of this solution. Curves of the average consolidation degree of the composite foundation under various nondimensional parameters were observed using the program based on the theoretical formula. Meanwhile, a series of in situ measurements including the settlement of pile and soil, the pore water pressure, and the total stress under embankment load were obtained on the CCSG pile composite foundation on a section of Zhenjiang-Liyang highway. The analyzed results show that the new style composite foundation patent technology has many advantages such as small differential postconstruction settlement (differential is not good, small is), reliable quality, high bearing capacity, and stability. And the consolidation of composite foundation is largely affected by the nondimensional parameters. The analytical solution is finally verified with the actual measurement data.
\end{abstract}

\section{Introduction}

Composite foundation technology has been widely used in the foundation treatment of soft soil. Concrete-cored sand-gravel pile composite foundation (CCSG pile composite foundation), which is composed by prefabricated lowgrade concrete-cored pile and sand-gravel shell, consisting of soil between piles, cushion, and the composite pile, is a new type of multivariate composite foundation that has been put forward in the recent years. Based on the idea of controlling and differentiating post-construction settlement, this foundation uses low-grade concrete-cored pile as the vertical reinforcement, sand-gravel shell as the vertical drainage body, and cushion as the horizontal drainage body, as shown in Figure 1. The outstanding advantages of this new style technology lie in using the concrete-cored sandgravel shell as the vertical drainage body to speed up the consolidation of soil between piles during construction and preloading periods, to control post-construction settlement and differential post-construction settlement within allowed extent in applied periods, and to make full use of the bearing capacity of soil between piles. A surcharge load larger than the structure load was adopted for preloading to accelerate the process of compression. In deep soft foundation treatment, the hierarchical heap load and the drainage reinforcement advantages of sand shell in preloading period help to speed up pore water pressure dissipation and degree of consolidation in soft soil. And the deep foundation compression consolidation effect is remarkable.

On the other hand, the consolidation theories for composite foundations reinforced by columns are developed on the basis of those well-drained foundations. The only difference between these theories is that the former one considers the stress concentration between soil and column but the latter does not. The most well-known theoretical study on the radial consolidation of vertical drains was carried out by Barron [1] firstly. A large number of studies have been conducted after. Recently, the consolidation of composite 


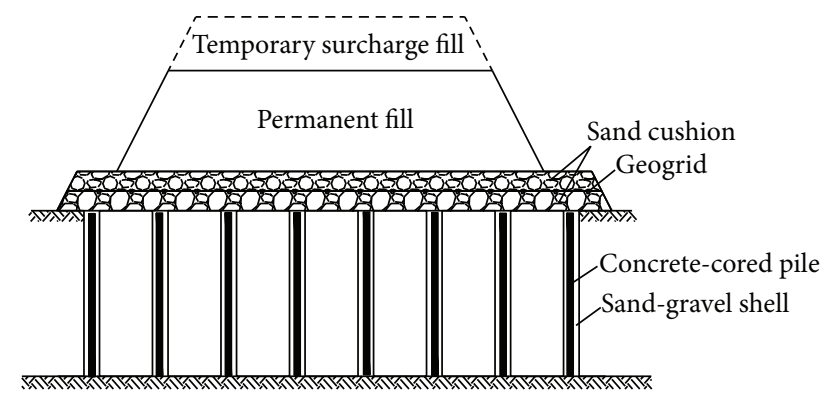

FIGURE 1: Schematic diagram of section.

foundation theory based on the sand drain consolidation theory has made great progress, with the consideration of the stress concentration phenomenon, well resistance, and smear effect. Goughnour and Bayuk [2] thought that composite foundation consolidation problem could be analyzed by the sand drain consolidation theory; Tang and Onitsuka [3] and Xie $[4,5]$ have established the consolidation equation for discrete material-pile composite foundation based on the equal strain assumption of Barron [1] and have also put forward the radial average degree of consolidation calculation formulae and the analytical solution of shaft drainage considering well resistance and the smudge effect. By incorporating the radial and vertical drainage in a coupling fashion, Leo [6] presented a series of closed-form solutions for equal strain consolidation of vertical drains subjected to instantaneous and ramp loading. The smear effect and well resistance were studied. Furthermore, this solution was extended by Lei et al. [7] to consider a time and depth-dependent loading. Zhu and Yin $[8,9]$ presented an analytical solution for the consolidation analysis of soil with a vertical drain under ramp loading considering the smear effect. Wang and Jiao [10] introduced the double porosity model into the analysis of vertical drain consolidation. With this approach, the variation of horizontal soil permeability can be depicted by an arbitrary function, which presents a relatively simple way to consider the gradual variation of soil permeability within the smear zone. Walker and Indraratna [11] have shown that the overlapping smear zone due to the reduction of drain spacing could also influence the drain performance. By incorporating the relationship of $e-\log \sigma^{\prime}$ and $e-\log k_{h}$, Indraratna et al. [12] found a new solution for the radial consolidation of vertical drains. Basu and Prezzi [13], Castro and Sagaseta [14] and Xie et al. $[15,16]$ utilized a stress increment independent of time and depth for the simplicity and effectiveness in solving engineering problems, in which the external load was assumed to be applied instantly and the corresponding stress increment resulted within the foundation was considered to be uniformly distributed along the column depth. A large number of laboratory studies [15-21] have shown that the coefficient of permeability within the smear zone was highly variable. To reflect the variability, some researchers included the gradual decay of horizontal permeability of soil toward the drain, such as linear decay in their analyses of vertical drain consolidation [22]. Recently, researchers have done lots of work on composite foundation [15, 16, 23-29]. A general

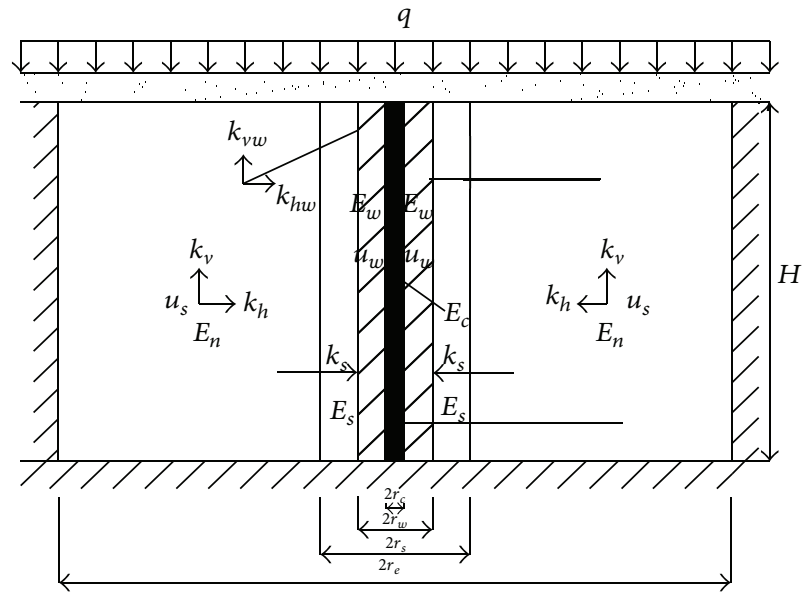

FIgURE 2: Computing model of single CCSG pile.

theoretical solution has been put forward for the consolidation of a composite foundation, and the consolidation theory has been presented for the composite foundation considering radial and vertical flows within the column, the variation of soil permeability within the disturbed soil zone, the depthvarying stress induced by multistage loading, and timeand depth-dependent stress increment along with different distribution patterns of soil permeability.

The above results have important reference value to study the reinforcement mechanism of composite foundation. But the studies of consolidation characteristic of CCSG pile composite foundation, which is new, under complicated conditions and multivariate, have not been reported yet. The authors have tried to study the consolidation calculation method of CCSG pile composite foundation in simple cases, but the influence factors of CCSG pile composite foundation consolidation characteristic are not considered, such as the change of horizontal penetration parameter in influence area, radial flow in sand shell, and the impervious character of low grade concrete core pile.

This paper introduces a series of field tests on CCSG pile composite foundation and the consolidation analysis model of CCSG pile composite foundation is established, which is based on equal strain hypothesis and considering the change of horizontal penetration parameters in influence zone and radial flow within sand-gravel shell. The consolidation general solution was obtained by the theoretical derivation. The analytical solution was finally validated with the data obtained from field tests and has verified the correctness of the theoretical solution.

\section{General Solution for Consolidation of CCSG Pile Composite Foundation}

2.1. Calculation Diagram. The idealized CCSG composite foundation is shown in Figure 2. In this figure, $H$ is the thickness of the soil; $r_{c}, r_{w}, r_{s}$, and $r_{e}$ are radius of the concrete-cored pile, the sand-gravel shell, the smear zone, and the influence zone (consisting of strong smear zone 
and weak smear zone), respectively; $E_{c}, E_{w}, E_{s}$, and $E_{n}$ are modulus of compressibility of the concrete-cored pile, the sand-gravel shell, the strong smear zone, and the weak smear zone respectively; $k_{s}$ and $k_{h}$ are the horizontal permeability coefficient of the strong smear zone and the weak smear zone, respectively; $k_{v}$ is the vertical permeability coefficient of soil; $k_{h w}$ and $k_{v w}$ are the horizontal and vertical permeability coefficient of sand-gravel shell, respectively; $u_{w}$ and $u_{s}$ are excess pore water pressures within the sand-gravel shell and in the soil; $q$ is external load.

2.2. Basic Assumptions. In order to obtain a simplified analytical solution, the following assumptions were made for the calculation.

(1) The relative displacement between CCSG pile and soil was ignored. The column and the surrounding soil were assumed to deform only vertically and had equal strain at same depth. Concrete-cored pile was simplified as an impervious cylindrical pile with the corresponding radius, and the interaction between the concrete-cored pile and the sand-gravel shell was also ignored.

(2) Darcy's law was obeyed.

(3) The soil within the scope of drainage influence zone was divided into strong smear zone and weak smear zone, in which the horizontal permeability coefficient changed along radial direction, as $k_{r}(r)$.

(4) The radial flow was taken into account in sand shell.

(5) The load was applied instantly. The additional stress of composite foundation distributed uniformly along the depth.

\subsection{Consolidation Equations and Solving Conditions}

2.3.1. Equilibrium Condition and Stress-Strain Relationship. In order to investigate the consolidation properties of CCSG pile composite foundation, the stress concentration effect should be considered, which concludes the stress of the concrete-cored pile and the sand-gravel shell, the excess pore water pressures of the sand-gravel shell, and the composite modulus of compression of the soil. At any time, both the column and the surrounding soil share the total stress in a composite foundation; that is,

$$
\begin{gathered}
\pi r_{c}^{2} \bar{\sigma}_{c}+\pi\left(r_{e}^{2}-r_{w}^{2}\right) \bar{\sigma}_{s}+\pi\left(r_{w}^{2}-r_{c}^{2}\right) \bar{\sigma}_{w}=\pi r_{e}^{2} \sigma_{0}, \\
\frac{\bar{\sigma}_{c}}{E_{c}}=\frac{\left(\bar{\sigma}_{s}-\bar{u}_{s}\right)}{E}=\frac{\left(\bar{\sigma}_{w}-\bar{u}_{w}\right)}{E_{w}}=\varepsilon_{v},
\end{gathered}
$$

where $\bar{\sigma}_{w}, \bar{\sigma}_{c}$, and $\bar{\sigma}_{s}$ are the average total stresses within the sand-gravel shell, the concrete-cored pile, and the soil, respectively, and $\sigma_{0}$ is the additional stress of composite foundation in any depth caused by the uniform load; $\varepsilon_{v}$ is the vertical strain of the column and the surrounding soil; $E=\left(\left(n^{2}-s^{2}\right) /\left(n^{2}-1\right)\right) E_{n}+\left(\left(s^{2}-1\right) /\left(n^{2}-1\right)\right) E_{s}$ is the composite modulus of compression of the soil; $\bar{u}_{s}$ and $\bar{u}_{w}$ are the excess pore water pressure within the soil and within the sand-gravel shell, respectively, which can be defined as

$$
\begin{gathered}
\bar{u}_{s}=\frac{\int_{r_{w}}^{r_{e}} 2 \pi r u_{s} d r}{\pi\left(r_{e}^{2}-r_{w}^{2}\right)}, \\
\bar{u}_{w}=\frac{\int_{r_{c}}^{r_{w}} 2 \pi r u_{w} d r}{\pi\left(r_{w}^{2}-r_{c}^{2}\right)},
\end{gathered}
$$

where $r$ is the radial distance away from the centre of concrete-cored pile.

From (1), $\varepsilon_{v}$ can be derived as

$$
\begin{aligned}
\varepsilon_{v} & =\frac{n^{2} \sigma_{0}-\left(n^{2}-1\right) \bar{u}_{s}-\left(1-a^{2}\right) \bar{u}_{w}}{E\left[\alpha+\left(n^{2}-1+Y\right)\right]} \\
& =\frac{n^{2} \sigma_{0}-\left(n^{2}-a^{2}\right) \bar{u}}{E\left[\alpha+\left(n^{2}-1+Y\right)\right]} .
\end{aligned}
$$

Derivation (4) about time is as follow

$$
\frac{\partial \varepsilon_{v}}{\partial t}=-\frac{n^{2}-a^{2}}{E\left[\alpha+\left(n^{2}-1+Y\right)\right]} \frac{\partial \bar{u}}{\partial t},
$$

where $\bar{u}$ is the total average excess pore water pressure in the soil at any depth, which can be defined as

$$
\begin{aligned}
\bar{u} & =\frac{1}{\pi\left(r_{e}^{2}-r_{c}^{2}\right)}\left(\int_{r_{c}}^{r_{w}} 2 \pi r u_{w} d_{r}+\int_{r_{w}}^{r_{e}} 2 \pi r u_{s} d_{r}\right) \\
& =\frac{\left[\left(1-a^{2}\right) \overline{u_{w}}+\left(n^{2}-1\right) \overline{u_{s}}\right]}{\left(n^{2}-a^{2}\right)} ;
\end{aligned}
$$

$s=r_{s} / r_{w}$ is the radius ratio of the drainage influence zone to the column; $n=r_{e} / r_{w}$ and $a=r_{c} / r_{w}$ are the radius ratio, respectively; $Y=E_{w} / E$ is the compression modulus ratio of the sand-gravel shell to the surrounding soil, $X=E_{c} / E$ is the compression modulus ratio of the concrete-cored pile to the surrounding soil; $\alpha=a^{2}(X-Y)$ is an expression.

2.3.2. Continuity Conditions of Seepage. The expression of the horizontal permeability coefficient of the soils in drainage influence zone that varies linearly with respect to the radial distance away from the column can be assumed to be

$$
k_{r}(r)=k_{h} f(r),
$$

where $k_{h}$ is the horizontal permeability coefficients of the weak smear zone and $f(r)$ is the function depending on radial distance away from column. The equation describes the variation pattern of the soil permeability along horizontal direction.

The concrete-cored pile of CCSG pile is set to be impervious pile and the sand-gravel shell is made of discrete material pile. The consolidation equations of the soil of composite 
foundation and the sand-gravel shell are used, which can be defined as

$$
\begin{array}{cc}
\frac{\partial}{\partial r}\left[\frac{r \cdot k_{r}(r)}{\gamma_{w}} \frac{\partial u_{s}}{\partial r}\right]=-r\left(\frac{\partial \varepsilon_{v}}{\partial t}+\frac{k_{v}}{\gamma_{w}} \frac{\partial^{2} \bar{u}_{s}}{\partial z^{2}}\right), & r_{w} \leq r \leq r_{e} \\
\frac{\partial}{\partial r}\left(\frac{r \cdot k_{h w}}{\gamma_{w}} \frac{\partial u_{w}}{\partial r}\right)=-r\left(\frac{\partial \varepsilon_{v}}{\partial t}+\frac{k_{v w}}{\gamma_{w}} \frac{\partial^{2} \bar{u}_{w}}{\partial z^{2}}\right), & r_{c} \leq r \leq r_{w},
\end{array}
$$

where $\gamma_{w}$ is the unit weight of water.

\subsubsection{Solving Conditions. Consider the following}

(1) $r=r_{e}, \partial u_{s} / \partial r=0$;

(2) $r=r_{w}, u_{s}=u_{w}$;

(3) $r=r_{c}, \partial u_{w} / \partial r=0$; (considering the concrete-cored pile as an impervious pile)

(4) $r=r_{w}, k_{r}\left(r_{w}\right)\left(\partial u_{s} / \partial r\right)=k_{h w}\left(\partial u_{w} / \partial r\right)$; (the radial velocity of pile- soil interface is equal).

The vertical boundary conditions can be written as

(5) $z=0, u_{w}=0, \bar{u}=0$;

(6) $z=H, \partial u_{w} / \partial z=0, \partial \bar{u} / \partial z=0$; (in single-drainage condition)

(7) $z=H, u=0, \bar{u}=0$; (in double-drainage condition).

Assuming that there is no deformation of the pile and the soil at initial time and the external load is bore all by pore water, so the initial condition can be written as $t=0, \bar{u}(z, 0)=$ $\sigma_{0}$.

2.4. The Establishment of the Governing Equations. Equation (10) can be obtained by integrating both sides of (8) about $r$ and using solving condition (1):

$$
\frac{\partial u_{s}}{\partial r}=\frac{\gamma_{w}}{2 k_{h}}\left(\frac{\partial \varepsilon_{v}}{\partial t}+\frac{k_{v}}{\gamma_{w}} \frac{\partial^{2} \bar{u}_{s}}{\partial z^{2}}\right)\left[\frac{r_{e}^{2}}{r f(r)}-\frac{r}{f(r)}\right] .
$$

Integrating both sides of (10) about $r$ again and using solving condition (2), the following can be obtained:

$$
\begin{aligned}
u_{s}(r)= & \left.u_{w}\right|_{r=r_{w}}+\frac{\gamma_{w}}{2 k_{h}}\left(\frac{\partial \varepsilon_{v}}{\partial t}+\frac{k_{v}}{\gamma_{w}} \frac{\partial^{2} \bar{u}_{s}}{\partial z^{2}}\right) \\
& \times\left[r_{e}^{2} A_{0}(r)-B_{0}(r)\right], \\
A_{0}(r)= & \int_{r_{w}}^{r} \frac{d \xi}{\xi f(\xi)}, \quad B_{0}(r)=\int_{r_{w}}^{r} \frac{\xi d \xi}{f(\xi)} .
\end{aligned}
$$

Equation (11) is substituted into (2):

$$
\bar{u}_{s}=\left.u_{w}\right|_{r=r_{w}}+\frac{r_{e}^{2} \gamma_{w} F_{c}}{2 k_{h}}\left(\frac{\partial \varepsilon_{v}}{\partial t}+\frac{k_{v}}{\gamma_{w}} \frac{\partial^{2} \bar{u}_{s}}{\partial z^{2}}\right),
$$

where $F_{c}=2\left(A_{1} r_{e}^{2}-B_{1}\right) / r_{e}^{2} r_{w}^{2}\left(n^{2}-1\right), A_{1}=\int_{r_{w}}^{r_{e}} r A_{0}(r) d r$, and $B_{1}=\int_{r_{w}}^{r_{e}} r B_{0}(r) d r$.
By integrating both sides of (9) about $r$ and using solving condition (3), the following is obtained:

$$
\frac{\partial u_{w}}{\partial r}=\frac{\gamma_{w}}{2 k_{h w}}\left(\frac{\partial \varepsilon_{v}}{\partial t}+\frac{k_{v w}}{\gamma_{w}} \frac{\partial^{2} \bar{u}_{w}}{\partial z^{2}}\right)\left(\frac{r_{c}^{2}}{r}-r\right) .
$$

Equation (14) is integrated about $r$ both sides to get

$$
\begin{aligned}
u_{w}(r)= & \left.u_{w}\right|_{r=r_{w}}+\frac{\gamma_{w}}{2 k_{h w}}\left(\frac{\partial \varepsilon_{v}}{\partial t}+\frac{k_{v w}}{\gamma_{w}} \frac{\partial^{2} \bar{u}_{w}}{\partial z^{2}}\right) \\
& \cdot\left[r_{w}^{2}\left(\frac{1}{2}+a^{2} \ln \frac{r}{r_{w}}\right)-\frac{1}{2} r^{2}\right] .
\end{aligned}
$$

Equation (15) is substituted into (3):

$$
\overline{u_{w}}=\left.u_{w}\right|_{r=r_{w}}+\frac{\gamma_{w} R}{8 k_{h w}}\left(\frac{\partial \varepsilon_{v}}{\partial t}+\frac{k_{v w}}{\gamma_{w}} \frac{\partial^{2} \bar{u}_{w}}{\partial z^{2}}\right),
$$

where $R=r_{w}^{2}\left[\left(4 a^{2} /\left(1-a^{2}\right)\right)\left(\ln r_{w}-a^{2} \ln a r_{w}\right)-2 a^{2}-4 a^{2} \ln r_{w}-\right.$ $\left.\left(1-a^{4}\right) /\left(1-a^{2}\right)+2\right]$.

Equation (13) minus (16) meanwhile combining the expression of $\bar{u}$ in (4) and (5) deduces

$$
\begin{aligned}
\bar{u}-\bar{u}_{w}= & -\frac{\left(n^{2}-1\right)}{E\left(\alpha+n^{2}-1+Y\right)}\left(\frac{r_{e}^{2} F_{c} \gamma_{w}}{2 k_{h}}-\frac{\gamma_{w} R}{8 k_{h w}}\right) \frac{\partial \bar{u}}{\partial t} \\
& +\frac{r_{e}^{2} F_{c} k_{v}}{2 k_{h}} \frac{\partial^{2} \bar{u}}{\partial z^{2}} \\
& -\left[\frac{\left(1-a^{2}\right)}{\left(n^{2}-a^{2}\right)} \frac{r_{e}^{2} F_{c} k_{v}}{2 k_{h}}+\frac{\left(n^{2}-1\right)}{\left(n^{2}-a^{2}\right)} \frac{R k_{v w}}{8 k_{h w}}\right] \frac{\partial^{2} \bar{u}_{w}}{\partial z^{2}} .
\end{aligned}
$$

Substituting (10) and (14) into solving condition (4), meanwhile combining (5), the equation can be deduced as

$$
\begin{aligned}
\frac{-\left(n^{2}-a^{2}\right)^{2}}{E\left(\alpha+n^{2}-1+Y\right)} \frac{\partial \bar{u}}{\partial t}= & \left(a^{2}-1\right) \frac{k_{v w}}{\gamma_{w}} \frac{\partial^{2} \bar{u}_{w}}{\partial z^{2}} \\
& -\left(n^{2}-1\right) \frac{k_{v}}{\gamma_{w}} \frac{\partial^{2} \bar{u}_{s}}{\partial z^{2}}
\end{aligned}
$$

Substituting the expression of $\bar{u}$ in (4) into (18) we get equation

$$
\frac{\partial^{2} \bar{u}_{w}}{\partial z^{2}}=A \frac{\partial \bar{u}}{\partial t}-B \frac{\partial^{2} \bar{u}}{\partial z^{2}}
$$

where $A=\left(n^{2}-a^{2}\right) \gamma_{w} /\left(1-a^{2}\right)\left(k_{v w}-k_{v}\right) E\left(\alpha+n^{2}-1+Y\right)$, $B=\left(n^{2}-a^{2}\right) k_{v} /\left(1-a^{2}\right)\left(k_{v w}-k_{v}\right)$.

Equation (19) is substituted into (17) and we get

$$
\bar{u}_{w}=\bar{u}+C \frac{\partial \bar{u}}{\partial t}-D \frac{\partial^{2} \bar{u}}{\partial z^{2}},
$$

where $C=\left(\gamma_{w}\left[\left(n^{2}-1\right) k_{v w}+k_{v}\right] / E\left(\alpha+n^{2}-1+\right.\right.$ $\left.Y)\left(k_{v w}-k_{v}\right)\right)\left[r_{e}^{2} F_{c} / 2 k_{h}+R\left(n^{2}-1\right) / 8 k_{h w}\right] D=\left(k_{v w} k_{v} /\left(k_{v w}-\right.\right.$ $\left.\left.k_{v}\right)\right)\left[r_{e}^{2} F_{c} / 2 k_{h}+\left(n^{2}-1\right) R /\left(1-a^{2}\right) 8 k_{h w}\right]$. 
Deduce from (20) as

$$
\frac{\partial \bar{u}_{w}}{\partial z^{2}}=\frac{\partial^{2} \bar{u}}{\partial z^{2}}+C \frac{\partial^{3} \bar{u}}{\partial t \partial z^{2}}-D \frac{\partial^{4} \bar{u}}{\partial z^{4}}
$$

Substituting (19) into (21) is deduced as

$$
D \frac{\partial^{4} \bar{u}}{\partial z^{4}}-C \frac{\partial^{3} \bar{u}}{\partial t \partial z^{2}}-(B+1) \frac{\partial^{2} \bar{u}}{\partial z^{2}}+A \frac{\partial \bar{u}}{\partial t}=0
$$

So far, the governing equations as (20) and (22) are obtained.

The solution can be obtained by using the method of separation of variables for (22), which can be expressed as

$$
\begin{gathered}
\bar{u}(z, t)=\sigma_{0} \sum_{m=1}^{\infty} \frac{2}{M} \sin \left(\frac{M}{H} z\right) e^{-\beta_{m} t}, \\
\bar{u}_{w}(z, t)=\sigma_{0} \sum_{m=1}^{\infty} \frac{2}{M}\left[1-C \beta_{m}+D\left(\frac{M}{H}\right)^{2}\right] \\
\cdot \sin \left(\frac{M}{H} z\right) e^{-\beta_{m} t}, \\
U=1-\sum_{m=1}^{\infty} \frac{2}{M^{2}} e^{-\beta_{m} t}
\end{gathered}
$$

where $M=((2 m+1) / 2) \pi,(m=0,1,2, \ldots)$,

$$
\begin{aligned}
& \beta_{m}=E\left(\alpha+n^{2}-1+Y\right)\{ k_{v w} k_{v}\left(\frac{M}{H}\right)^{2} \\
& \times\left[\frac{r_{e}^{2} F_{c}}{2 k_{h}}+\frac{\left(n^{2}-1\right) R}{\left(1-a^{2}\right) 8 k_{h w}}\right] \\
&\left.+\left[\left(n^{2}-1\right) k_{v}+k_{v w}\right]\right\} \\
& \times\left(\gamma _ { w } \left\{\frac{\left(n^{2}-a^{2}\right)^{2}}{1-a^{2}} \cdot\left(\frac{H}{M}\right)^{2}+\left[\left(n^{2}-1\right) k_{v w}+k_{v}\right]\right.\right. \\
&\left.\left.\times\left[\frac{r_{e}^{2} F_{c}}{2 k_{h}}+\frac{\left(n^{2}-1\right) R}{8 k_{h w}}\right]\right\}\right)^{-1} .
\end{aligned}
$$

In order to verify the rationality of the assumptions and the methods of the consolidation in this paper, the consolidation solution can be degraded.

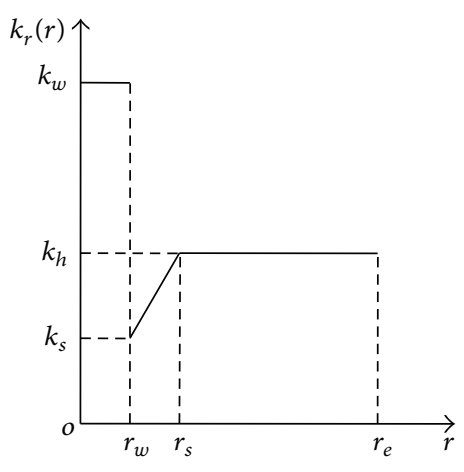

FIGURE 3: Five variation patterns of horizontal permeability coefficient in smear zone.

When $X=1$ and $a=0, \beta_{m}$ changes into

$$
\begin{aligned}
& \beta_{m}=E\left(n^{2}-1+Y\right)\left\{k_{v w} k_{v}\left(\frac{M}{H}\right)^{2}\right. \\
& \times {\left[\frac{r_{e}^{2} F_{c}}{2 k_{h}}+\frac{\left(n^{2}-1\right) r_{w}^{2}}{8 k_{h w}}\right] } \\
&\left.+\left[\left(n^{2}-1\right) k_{v}+k_{v w}\right]\right\} \\
& \times\left(\gamma _ { w } \left\{n^{4}\left(\frac{H}{M}\right)^{2}+\left[\left(n^{2}-1\right) k_{v w}+k_{v}\right]\right.\right. \\
&\left.\left.\times\left[\frac{r_{e}^{2} F_{c}}{2 k_{h}}+\frac{\left(n^{2}-1\right) r_{w}^{2}}{8 k_{h w}}\right]\right\}\right)^{-1} .
\end{aligned}
$$

This is the consolidation solution of common composite foundation provided by $\mathrm{Lu}$ et al. [30] that considered the radial flow within the pile.

When $Y=1, k_{v}=k_{v w}$, and $k_{h}=k_{h w}, \beta_{m}$ and $U$ change into

$$
\begin{gathered}
\beta_{m}=\frac{k_{v} E}{\gamma_{w}}\left(\frac{M}{H}\right)^{2}=c_{v}\left(\frac{M}{H}\right)^{2}, \\
U=1-\sum_{m=1}^{\infty} \frac{2}{M^{2}} e^{-M^{2} T_{v}},
\end{gathered}
$$

where $c_{v}=k_{v} E / \gamma_{w}, T_{v}=c_{v} t / H^{2}$.

This is the one-dimensional consolidation solution of Terzaghi's theory. The rationality of the consolidation solution in this paper can be reflected through the above answer to degradation.

From (13), (23), and (25), it can be seen that the influence of horizontal permeability coefficient in the influenced zone to the consolidation solution is reflected mainly by the parameter $F_{c}$, which is related to the changing pattern of horizontal permeability coefficient. Figure 3 displays a typical 
changing pattern of horizontal permeability coefficient versus $r$. The solutions of $F_{c}$ had been given by Zhang et al. [24] as

$$
\begin{aligned}
F_{c}=\frac{n^{2}}{n^{2}-1}\{ & \frac{s-1}{\kappa s-1} \ln (\kappa s)-\frac{(s-1)^{2}}{n^{2}(1-\kappa)} \\
& +\frac{2}{n^{2}} \frac{(s-1)(\kappa s-1)}{(1-\kappa)^{2}} \ln \frac{1}{\kappa}-\frac{2}{n^{4}} \frac{s-1}{1-\kappa} \\
& \times\left(\frac{s^{3}-1}{3}-\frac{s^{2}-1}{3}\right)-\frac{1}{n^{4}} \frac{(s-1)(\kappa s-1)}{(1-\kappa)^{2}} \\
& \times\left[\frac{s^{2}-1}{2}-\frac{(s-1)(\kappa s-1)}{1-\kappa}\right. \\
& \left.+\frac{(\kappa s-1)^{2}}{(1-\kappa)^{2}} \ln \frac{1}{\kappa}\right] \\
& +\frac{n^{2}-s^{2}(1-s)^{2}}{n^{4}}+\frac{n}{1-\kappa}-\frac{3}{s} \\
&
\end{aligned}
$$

\section{Parametric Study and Discussion}

In order to study the characters of consolidation of CCSG pile composite foundation, $\beta_{m}$ should be converted to dimensionless, which can be expressed as

$$
\beta_{m} t=\tau_{m} T_{h}
$$

where $T_{h}$ is the horizontal time factor of the soil, which can be expressed as

$$
T_{h}=\frac{c_{h} t}{4 r_{e}^{2}}, \quad c_{h}=\frac{E k_{h}}{\gamma_{w}} .
$$

In this case, (25) changes into

$$
U=1-\sum_{m=1}^{\infty} \frac{2}{M^{2}} e^{-\tau_{m} T_{h}}
$$

where

$$
\begin{aligned}
\tau_{m}= & r_{e}^{2}\left(\alpha+n^{2}-1+Y\right) \\
& \times\left\{\frac{k_{v w}}{k_{h}}\left(\frac{M}{H}\right)^{2}\left[\frac{r_{e}^{2} F_{c}}{2}+\frac{\left(n^{2}-1\right) R k_{h}}{\left(1-a^{2}\right) 8 k_{h w}}\right]\right. \\
& \left.+\left(n^{2}-1\right)+\frac{k_{v w}}{k_{v}}\right\}
\end{aligned}
$$

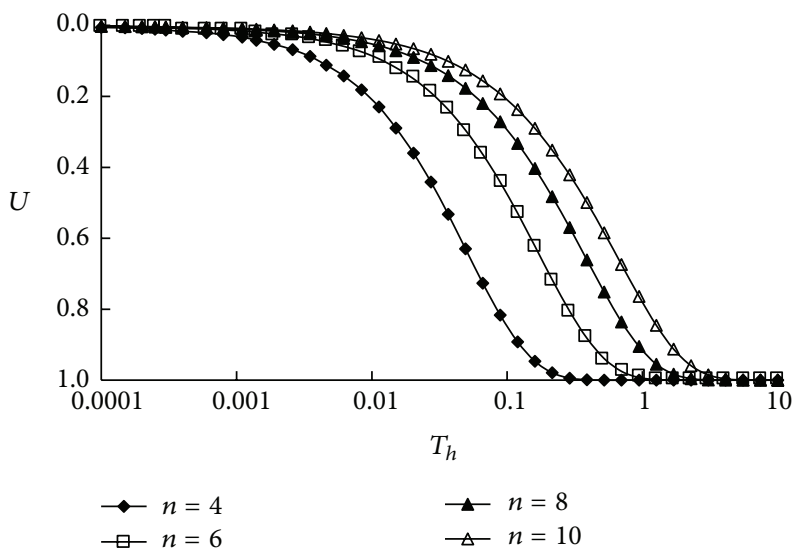

FIGURE 4: Influence of $n$ on consolidation process.

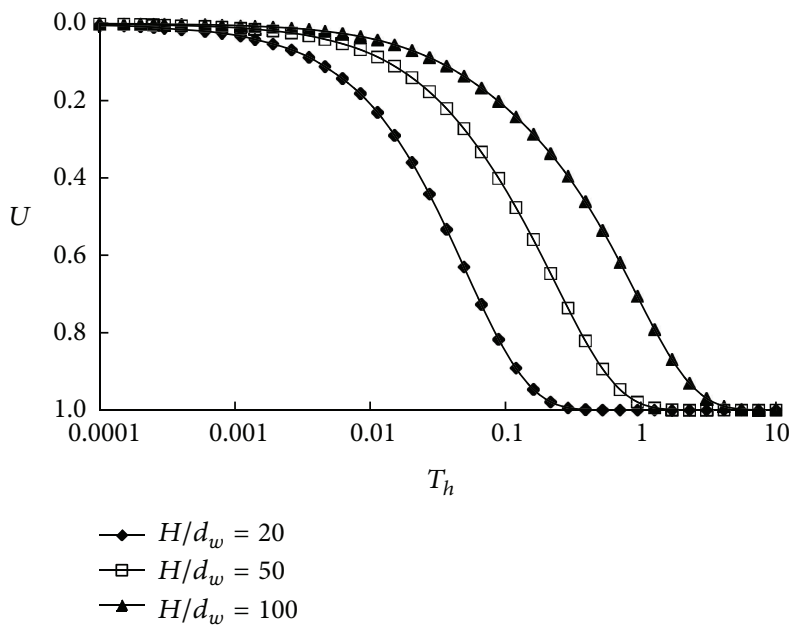

FigURE 5: Influence of $H / d_{w}$ on consolidation process.

$$
\begin{gathered}
\times\left(\left\{\frac{\left(n^{2}-a^{2}\right)^{2}}{1-a^{2}} \cdot \frac{k_{h}}{k_{v}}\left(\frac{H}{M}\right)^{2}\right.\right. \\
+\left[\left(n^{2}-1\right) \frac{k_{v w}}{k_{v}}+1\right] \\
\left.\left.+\left(\frac{r_{e}^{2} F_{c}}{2}+\frac{R\left(n^{2}-1\right) k_{h}}{8 k_{h w}}\right)\right\}\right)^{-1} .
\end{gathered}
$$

From the expression of $\tau_{m}$, the dimensionless parameters influencing the consolidation character of CCSG pile composite foundation include $n, a, s, X, Y, H / d_{w}\left(d_{w}=2 r_{w}\right)$, $k_{h} / k_{v}, k_{s} / k_{h}, k_{h} / k_{v w}, k_{h} / k_{h w}$, and $k_{h w} / k_{v w}$. The influences of several dimensionless parameters on the consolidation behaviour of CCSG pile composite foundation were investigated and some numerical results from different solutions were compared according to the above formula. The specific calculation results are shown in Figures 4-11. The calculating parameters are shown in Table 1. 
TABLE 1: Parameters used for calculation $(I)$.

\begin{tabular}{lcccccccccc}
\hline Figure no. & $n$ & $a$ & $s$ & $H / d_{w}$ & $X$ & $Y$ & $k_{s} / k_{h}$ & $k_{h} / k_{v}$ & $k_{h} / k_{v w}$ & $k_{h w} / k_{v w}$ \\
\hline 4 & - & 0.2 & 1.5 & 20 & 1000 & 10 & 0.6 & 2 & 0.001 & 1 \\
5 & 4 & 0.2 & 1.5 & - & 1000 & 10 & 0.6 & 2 & 0.001 \\
6 & 4 & 0.2 & 1.5 & 20 & 1000 & 10 & 0.2 & 2 & 0.001 \\
7 & 4 & - & 1.5 & 20 & - & - & 0.6 & 2 & 0.001 \\
8 & 4 & 0.2 & 1.5 & 20 & - & - & 0.2 & 2 & 0.001 \\
9 & 4 & 0.2 & 1.5 & 20 & 1000 & 10 & 0.2 & 2 & 1 \\
10 & 4 & 0.2 & 1.5 & 20 & 1000 & 10 & - & 2 & 0.001 & 1 \\
11 & 4 & 0.2 & 1.5 & 20 & 1000 & 10 & - & 2 & 1 \\
\hline
\end{tabular}

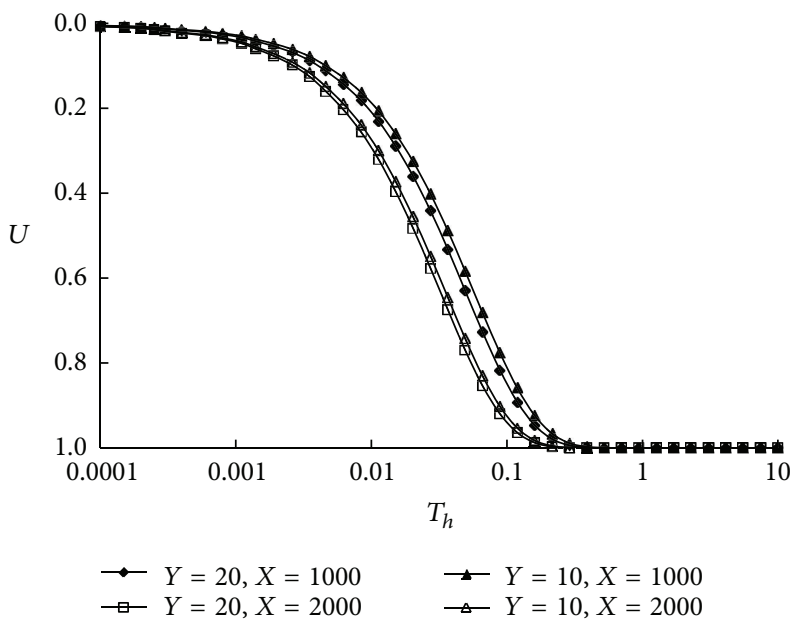

Figure 6: Influence of $X$ and $Y$ on consolidation process.

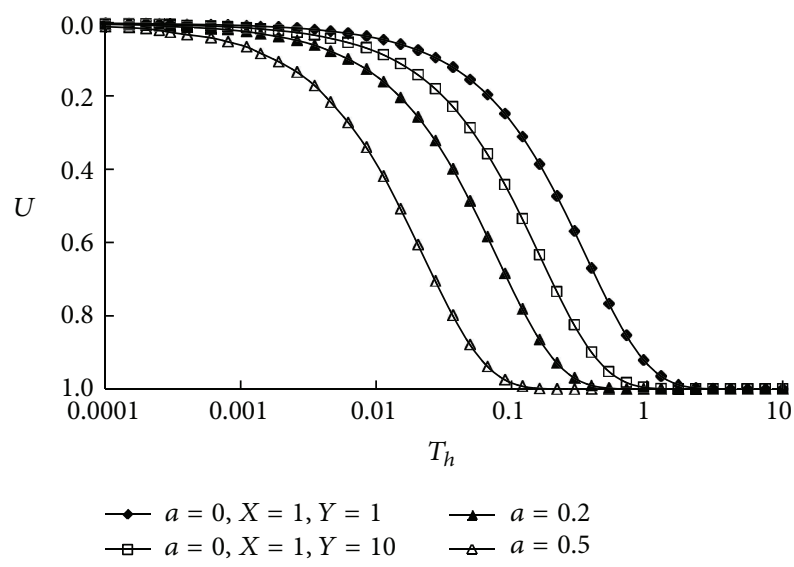

FIGURE 7: Influence of $a$ on consolidation process.

Figures 4 and 5 show the influence of $n$ and $H / d_{w}$ on consolidation behaviour of CCSG pile composite foundation. It can be seen that consolidation velocity is reduced with the increase of $n$ and $H / d_{w}$. In other words, the bigger the scope of influenced zone, the slower the consolidation rate is. Figure 4 also shows that the reducing rate of consolidation velocity decreases with the increase of $n$.

Figure 6 shows the influence of $X$ and $Y$ on the consolidation behaviour of CCSG pile composite foundation. As shown in the figure, when the value of $Y$ is constant, the

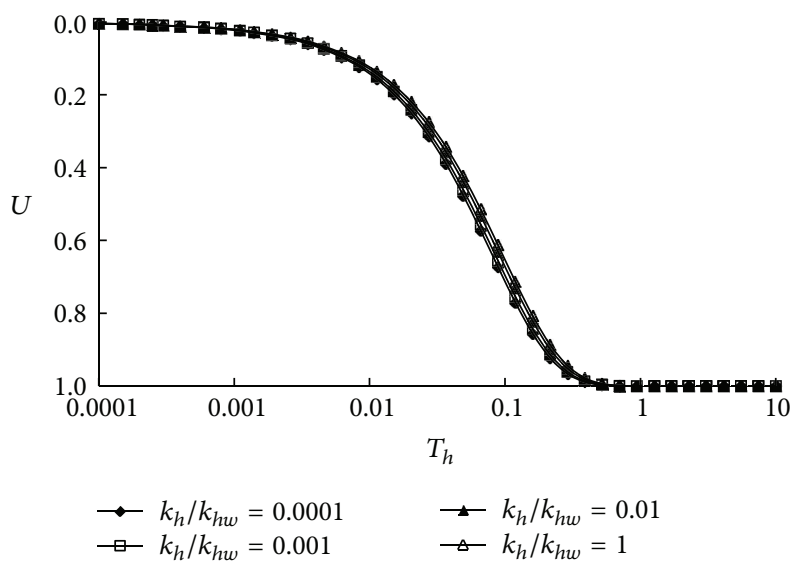

FIGURE 8: Influence of $k_{h} / k_{h w}$ on consolidation process.

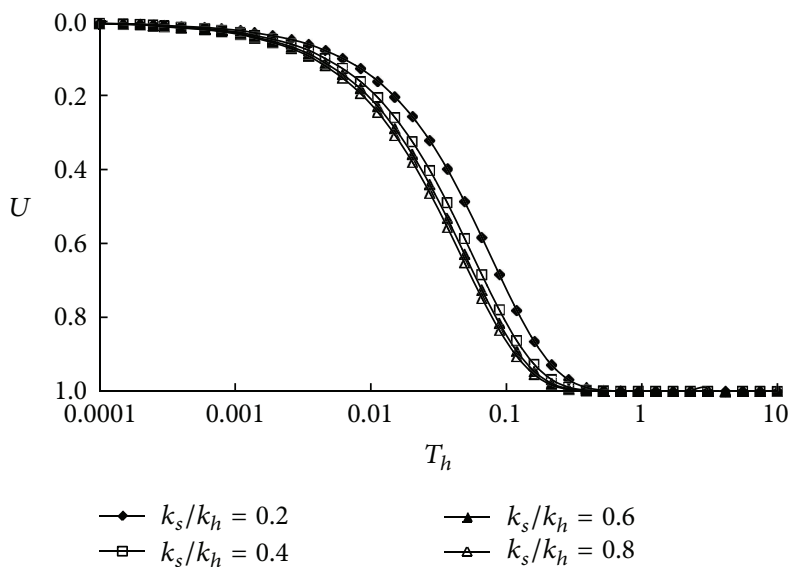

FIGURE 9: Influence of $k_{s} / k_{h}$ on consolidation process.

consolidation rate increases with the value of $X$. Similarly, with $X$ constant, the larger the value of $Y$, the faster the consolidation rate is. So, the consolidation rate should be accelerated with the increasing of $X$ and $Y$.

Figure 7 shows the comparison between several solutions, including the solution for ordinary granular material pile composite foundation proposed by Lu et al. [26] and Terzaghi's solution for natural foundation. When $a=0, X=1, Y=$ $1, k_{v}=k_{v w}$, and $k_{h}=k_{h w}$, the curve presents the changing of consolidation degree with time for natural foundation. When 


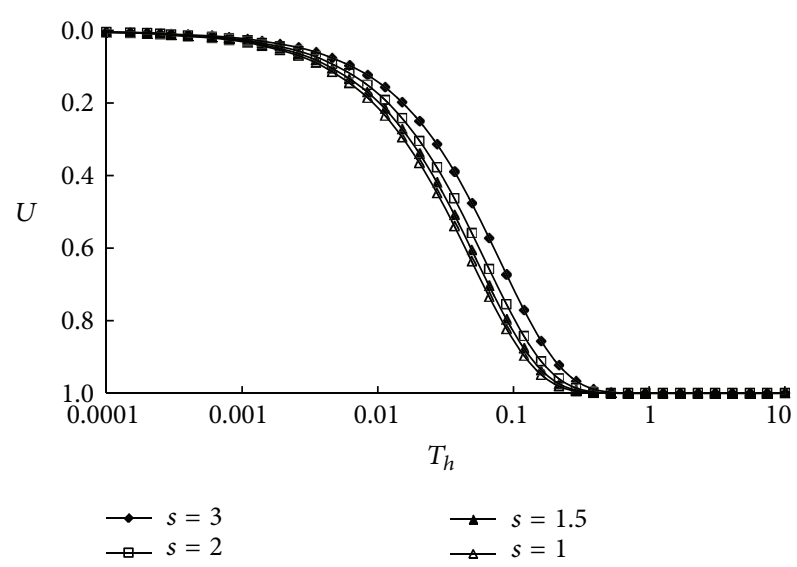

FIGURE 10: Influence of $s$ on consolidation process.

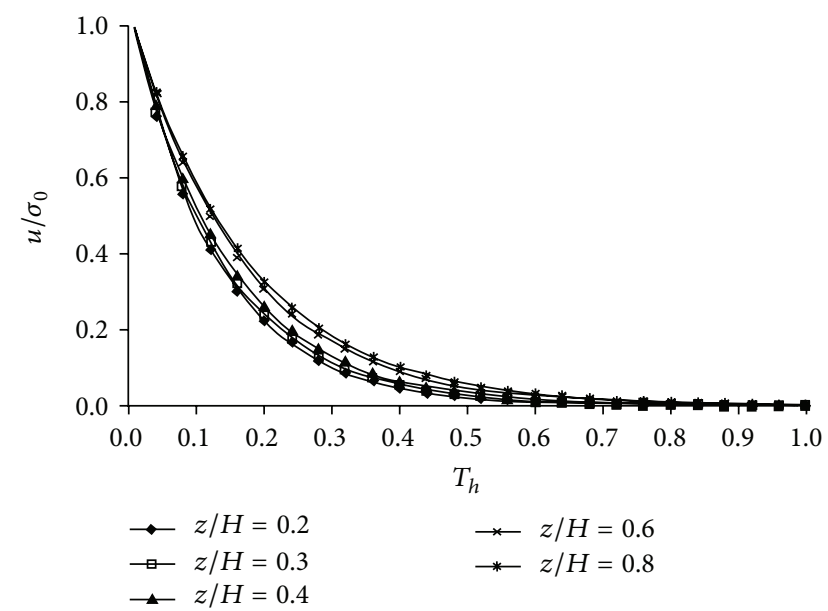

FIGURE 11: Dissipation curves of average pore-pressure at different depth in foundation.

$a=0, X=1$, and $Y=10$, the curve shows the changing of consolidation degree with time for ordinary granular material pile composite foundation. The curves of $a=0.2$ and $a=0.5$ are the consolidation degree curves changing with time of CCSG pile composite foundation. Among these solutions, only the solution presented in this study takes the characters of CCSG pile composite foundation into account. As shown in Figure 7, the consolidation rates given by the present solution are greater than those given by the other solutions. It also can be seen that the consolidation rates given by the present solution and the Lu et al. [26] solution are both greater than that given by Terzaghi's solution because the former two solutions both take the stress concentration from soil to column into account. These conclusions indicate that CCSG pile composite foundation performs best in the drainage consolidation. Because CCSG pile composite foundation has large diameter of the drainage channel, and the concrete-core pile as vertical reinforcement, the postloading settlement of the foundation finished quickly. In addition, the larger the value of $a$, the faster the consolidation rate of CCSG pile composite foundation is. So, the consolidation rate should be accelerated with the increase of $a$. However, when the value of $a$ reaches 1, CCSG pile composite foundation will convert to pile foundation and has no drainage function.

Figure 8 shows the influence of $k_{h} / k_{h w}$ on consolidation behaviour of CCSG pile composite foundation under three different patterns of horizontal permeability coefficient. It can be seen that when the horizontal permeability coefficient within soil is smaller than that within the sand-gravel shell, the consolidation rate is accelerated limited with the decrease of $k_{h} / k_{h w}$. In addition, the curves of consolidation degree are close to each other, which indicate that the influence of $k_{h} / k_{h w}$ on consolidation behaviour of CCSG pile composite foundation is weak. As the concrete-cored pile is considered as an impervious pile, both the solutions of the soil and sandgravel shell are obtained using the consolidation equations, so taking the radial flow within sand-gravel shell into account is necessary.

Figure 9 shows the influence of $k_{s} / k_{h}$ on consolidation behaviour of CCSG pile composite foundation under the change of horizontal permeability coefficient of the soil. The value of $k_{s} / k_{h}$ can reflect the intensity of disturbance to the surrounding soil during column construction: the bigger the value is, the more the disturbance intensity is. It can be seen from Figure 9 that the consolidation rate of a composite foundation reduces with the decrease of $k_{s} / k_{h}$. In other words, the consolidation rate of a composite foundation is enhanced by reducing the disturbance intensity.

Figure 10 shows the influence of $s$ on consolidation behaviour of CCSG pile composite foundation, which represents the size of the disturbed zone. It can be seen from the graph that the consolidation rate of a composite foundation reduces with the increase of $s$. In another word, the larger the disturbance area, the slower the consolidation rate is.

Figure 11 represents the average pore-pressure dissipation. It can be seen from the graph that the deeper the depth of foundation, the slower the pore-pressure dissipation speed is, which means slow consolidation rate of deep foundation and is consistent with the actual situation.

\section{Case Application}

4.1. Survey of Experimental Sections. The construction section, Liyang Second Bid of Zhenjiang, Liyang Highway, is located in the Yangtze River valley. The area of treated embankment of thick and soft ground in section K63 + 046 $\mathrm{K} 63+087$ was $41 \mathrm{~m} \times 63 \mathrm{~m}$, which was $2583 \mathrm{~m}^{2}$. The CCSG pile composite foundation treatment was adopted, with a diameter of $50 \mathrm{~cm}$ (the prefabricated low-grade concretecored pile was $20 \mathrm{~cm} \times 20 \mathrm{~cm}$, and the outside diameter of the sand-gravel shell was $50 \mathrm{~cm}$ ) and a length of $22 \mathrm{~m}$. The piles were prefabricated in 3 parts and arranged in equilateral triangle, with $2.1 \mathrm{~m}$ spacing between section $\mathrm{K} 63+046$ and $\mathrm{K} 63+066$ and $1.9 \mathrm{~m}$ between section $\mathrm{K} 63+066$ and $\mathrm{K} 63+087$. One layer of hardcore bed with $50 \mathrm{~cm}$ thickness was placed as cushion together with one layer of geogrid after the construction of concrete-cored sand-gravel pile. The ground altitude was $3.1 \mathrm{~m}$, the designed altitude at the centre of roadbed superface was $8.5 \mathrm{~m}$, and the surcharge 
TABle 2: Physical and mechanical parameters of soils.

\begin{tabular}{|c|c|c|c|c|c|c|c|c|c|c|c|c|}
\hline \multirow{2}{*}{$\begin{array}{l}\text { Soil } \\
\text { layer }\end{array}$} & \multirow{2}{*}{$\begin{array}{l}\text { Name of soil } \\
\text { layer }\end{array}$} & \multirow{2}{*}{$\begin{array}{l}\text { Soil layer } \\
\text { thickness/m }\end{array}$} & \multirow{2}{*}{$\omega / \%$} & \multirow{2}{*}{$\gamma /\left(\mathrm{kN} / \mathrm{m}^{3}\right)$} & \multirow{2}{*}{$e_{0}$} & \multirow{2}{*}{$I_{P}$} & \multirow{2}{*}{$I_{L}$} & \multirow{2}{*}{$\alpha_{(1-2)} / \mathrm{MPa}^{-1}$} & \multirow{2}{*}{$E_{s(1-2)} / \mathrm{MPa}$} & \multicolumn{2}{|c|}{ Direct shear (Quick shear) } & \multirow{2}{*}{$f_{\mathrm{ak}} / \mathrm{kPa}$} \\
\hline & & & & & & & & & & $c / \mathrm{kPa}$ & $\varphi /\left(^{\circ}\right)$ & \\
\hline (1) & $\begin{array}{l}\text { Miscellaneous } \\
\text { fill }\end{array}$ & $2.0 \sim 3.7$ & & & & & & & & & & \\
\hline (2) & Silty clay & $1.6 \sim 2.6$ & 32.3 & 18.4 & 0.91 & 10.7 & 1.01 & 0.30 & 7.28 & 2.0 & 17.1 & 125 \\
\hline (3) & Muddy silty clay & $6.6 \sim 10.9$ & 38.8 & 17.9 & 1.07 & 11.7 & 1.35 & 0.49 & 4.47 & 7.0 & 24.5 & 65 \\
\hline (4)-1 & Silty clay-silt & $0.6 \sim 2.5$ & 35.2 & 18.3 & 0.96 & 11.6 & 1.27 & 0.45 & 5.37 & 18.0 & 16.5 & 105 \\
\hline (4) -2 & Silt-silty clay & $0.7 \sim 2.9$ & 33.9 & 18.5 & 0.93 & 10.9 & 1.35 & 0.41 & 5.68 & 10.0 & 25.5 & 150 \\
\hline (4) -3 & Silty clay-silt & $0 \sim 4.4$ & 26.6 & 19.3 & 0.75 & 11.7 & 0.76 & 0.45 & 3.94 & 25.0 & 13.7 & 165 \\
\hline (5) & Silty clay & $9.6 \sim 10.1$ & 35.0 & 18.7 & 0.93 & 13.0 & 1.16 & 0.43 & 5.29 & 13.0 & 12.2 & 105 \\
\hline (6) & Angular pebbles & & & & & & & & & & & 250 \\
\hline
\end{tabular}

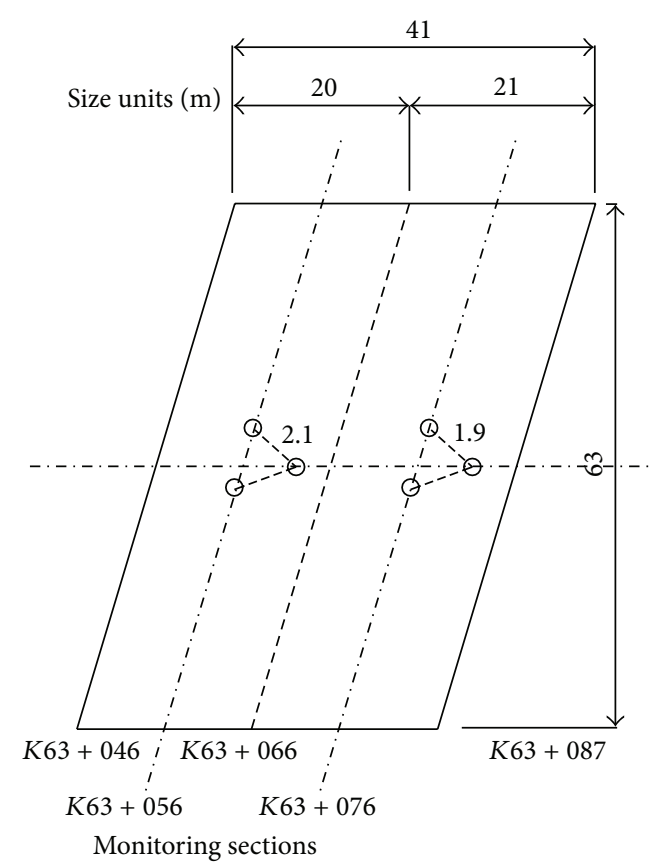

FIgURE 12: Test section layout drawing.

preloading altitude was $11.1 \mathrm{~m}$. The maximum dry density of embankment filler was $1.84 \mathrm{~g} / \mathrm{m}^{3}$, and the slope of the embankment was $1: 2$. The subgrade was $35 \mathrm{~m}$ wide, and the groundwater level was $1 \sim 2 \mathrm{~m}$ below surface. Vibrating sunk-tube method was used for construction. According to exploratory boring, CPT, vane shear test and geotechnical parameter test, the physical and mechanical parameters of soils in experimental sections are shown in Table 2. The layout of tested section is shown in Figure 12.

The profile map of instruments at site monitored section is shown in Figure 13. The layout of instruments at each section was as follows.

(1) Three ground settlement poles were placed in the left, middle, and right position along the width of the subgrade, respectively.

(2) One 30-meter long layered settlement pile was embedded at subgrade centre. Twelve settlement rings were layered on the pile every two meters along the depth. Meanwhile, nine pore-pressure detectors were embedded every two meters along the depth.

(3) One inclinometer pile was embedded at subgrade slope.

(4) Ten soil pressure boxes were embedded in the pile top, the sand top, and the soil, respectively, at the triangular area consisting of three piles at the subgrade centre.

(5) Six steel bar stress detectors including one at pile top, one at pile bottom, and four at pile body were embedded in each pile of the two chosen piles.

\subsection{Comparative Analysis of the Engineering Example}

4.2.1. Settlement of Pile Top and Soil. Three settlement meters were embedded in the right and left shoulders and the centre of section K63 + 056 and $\mathrm{K} 63+076$, respectively, to measure the settlement of soils. Meanwhile another two meters were embedded in the concrete-cored pile top in the centre of section $\mathrm{K} 63+056$ and $\mathrm{K} 63+076$, respectively, to measure the settlement of concrete-cored pile top. Settlement meters with a size of $70 \mathrm{~cm} \times 70 \mathrm{~cm}$ were used in the soil. To prevent from interfering with the settlement of the concrete-cored pile and to avoid the deflection of the settlement meter on the top of the pile, meters with a size the same as the concrete-cored pile section, which was $20 \mathrm{~cm} \times 20 \mathrm{~cm}$, were used on the top of the pile and were welded to the top directly. Settlement observation points were set up on tops of the sand-gravel shell and concrete-cored pile. Stable control point was established to measure the elevation changes with high precision water level. The measurement reading was obtained daily in the early stage of construction and then in every two or three days after the reading was stable for the settlement-time curve. The settlement observation process lasted for 285 days. The variation of settlement in soil in the centre of section K63 + 056 and K63 + 076 is shown in Figure 14 .

From Figure 14, by comparing the settlement of section $\mathrm{K} 63+056$ and $\mathrm{K} 63+076$, it can be seen that until the end, the settlement in the centre of the section K63+056, which was farther away from the abutment, was $64.9 \mathrm{~cm}$, and the other one was $47.9 \mathrm{~cm}$. The result indicates that the bigger the 


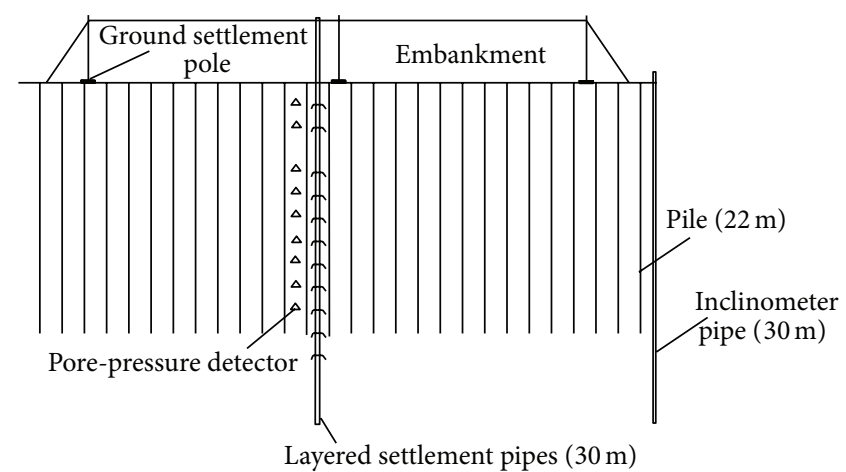

(a) The layout section of monitoring section instruments

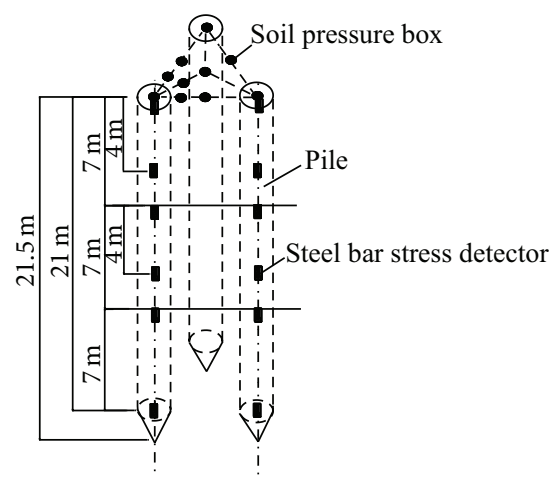

(b) The layout drawing of earth pressure boxes and steel bar stress detectors

Figure 13: Profile drawing of instruments.

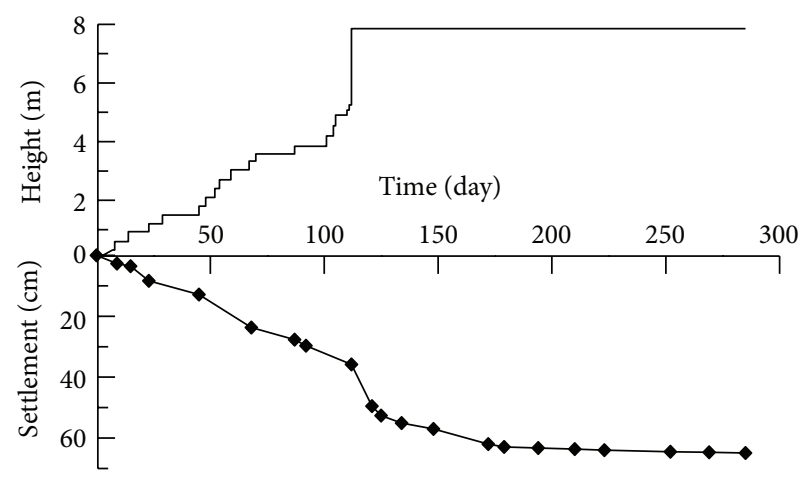

(a) K63+056 Section centre

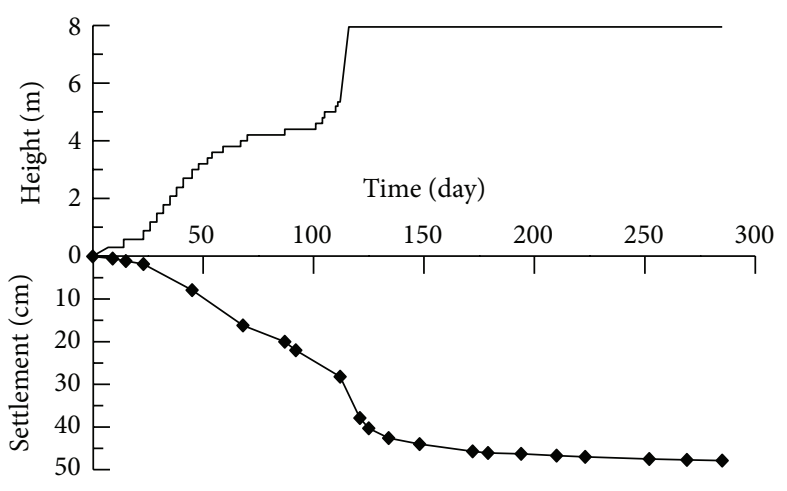

(b) K63 + 076 Section centre

FIgURE 14: Settlement of soil surface.

pile spacing is, the bigger the settlement ratio and settlement are, which also reflects the influence of the pile spacing on the composite foundation settlement. During the construction of embankment (the first 110 days), the maximum settlement rates at section $\mathrm{K} 63+056$ and $\mathrm{K} 63+076$ were $0.6 \mathrm{~cm}$ and $0.4 \mathrm{~cm}$ per day, respectively. During the period of preloading (the next 10 days), the maximum settlement rate at section $\mathrm{K} 63+056$ was $1.5 \mathrm{~cm}$ per day and was $1.1 \mathrm{~cm}$ per day at section $\mathrm{K} 63+076$. As shown in Figure 14, the settlement curves became horizontal straight, while the maximum lateral displacement was only $1 \mathrm{~mm}$ per day by now, indicating that the immediate settlement of soil was larger. After the applying of dead load, the settlement rate tended to reduce steadily. The first-measured settlement rate was $5 \mathrm{~mm}$ per month after dead load had been applied for four months indicating that the surface settlement had become steady.

In order to validate the theoretical formula derived in this paper, the construction data of the testing section and the field measured data at section $\mathrm{K} 63+076$ were used for calculating validation and contrastive analysis.

Asaoka method was used to predict the final settlement of composite foundation according to the settlement data measured from section $\mathrm{K} 63+076$. Then, the field test curve of overall average consolidation degree of CCSG pile composite foundation changing with time was obtained. Finally, the formula in this paper was amended using the improved Terzaghi method to satisfy the conditions of step loading in practical engineering.

As shown in Figure 15, the manner of the theoretical curve of average consolidation degree changing with time is similar to that of the curve obtained from field test. The hysteresis phenomenon is due to the existing settlement hysteresis after completion of loading. From the figure, it can be seen that the consolidation rate given by the solution in this paper is greater than that deduced from field test data. Considering the error between the observation and test, a good agreement can be affirmed, which validates the theoretical solution in this paper.

4.2.2. Pore Water Pressure. The steel-string type porepressure detector was used to monitor the pore-pressure, with a measuring range up to $200 \mathrm{kPa}$ or $400 \mathrm{kPa}$. Frequency meter was used to sense the frequency. In order to determine the instrument sensitivity coefficient, temperature coefficient, and sealing performance, the instruments were checkedout and calibrated before being embedded. The embedded way was stated in Section 4.1. Nine pore-pressure detectors were embedded at different depth at section $\mathrm{K} 63+056$ and $\mathrm{K} 63+076$, respectively. No test results were obtained from section $\mathrm{K} 63+076$ as the one detector was damaged during 


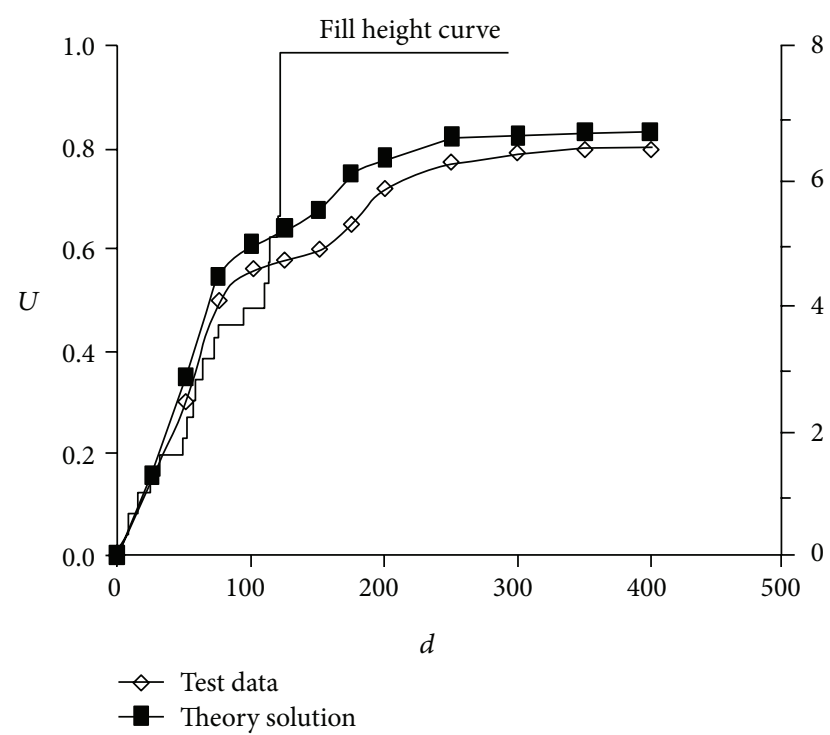

FIGURE 15: Variation of consolidation degree of the composite foundation.

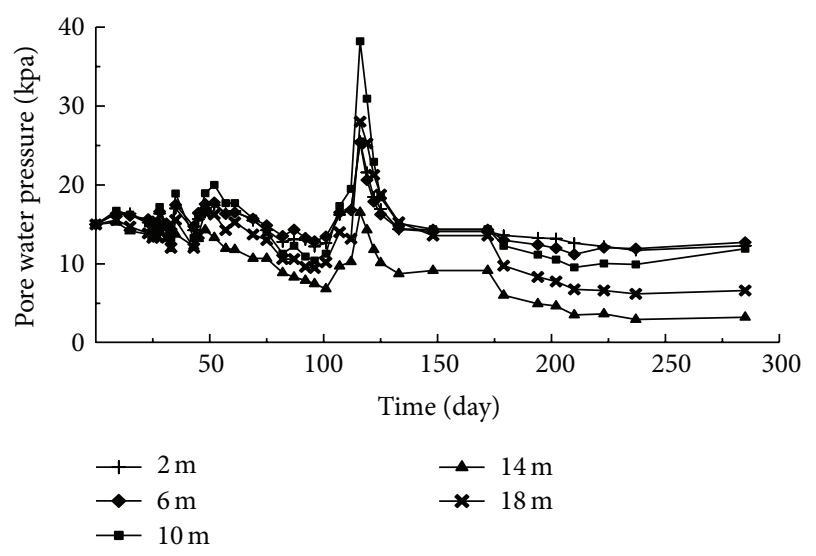

FIGURE 16: Excess pore water pressure with depth.

the abutment excavation. The observation of pore-pressure went on in parallel with the observation of soil pressure. The observation results of pore water pressure at primary depth at section K63+056 were shown in Figure 16.

As shown in Figure 16, at the first three months, with a filling height of $4.2 \mathrm{~m}$, the variation curves of pore-pressure were smooth. From day 100 to day 120, the filling height rose from $4.2 \mathrm{~m}$ to $7.9 \mathrm{~m}$, and the pore-pressure at different depth went up by 9 $28 \mathrm{kPa}$; meanwhile, the steep and sharp variation occurred on the curves. After dead load on day 120, the pore-pressure dissipated rapidly. From the entire depth range, the pore-pressure did not decrease with the increase of depth, and the measured maximum pore-pressure was at the depth of $10 \mathrm{~m}$ below surface. The drainage effect of concrete-cored sand gravel pile is very excellent, which could be obtained by the phenomenon that pore-pressure rose and dissipated rapidly.

Figure 17 shows the excess pore water pressure obtained by the amended theoretical equation. The figure is similar

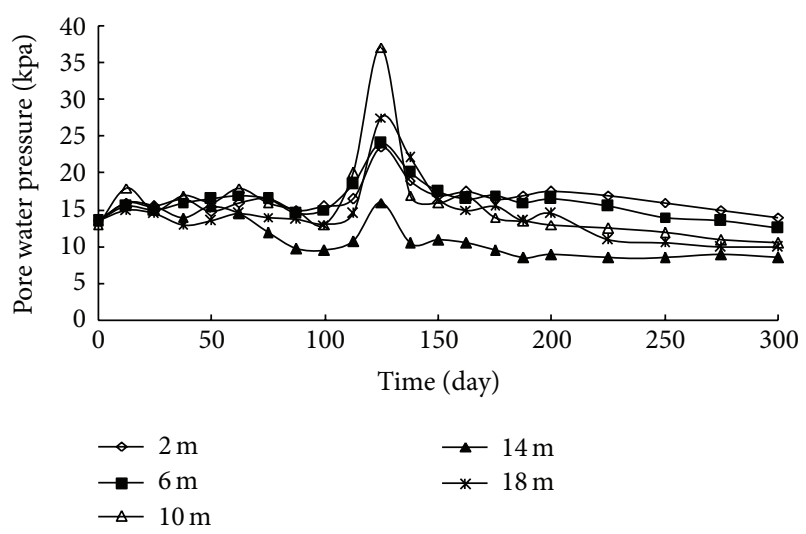

FIGURE 17: Excess pore water pressure with depth obtained by the theoretical equation.

to Figure 16, which indicates the validity of the theoretical equation in this paper.

4.2.3. Soil Pressure under Embankment Load. Ten soil pressure boxes were embedded in the triangular area consisting of three piles in the centre of section $\mathrm{K} 63+056$ and $\mathrm{K} 63+076$, respectively, including three on the top of the pile, three on the top of sand-gravel, and four in the soil between piles. The pressure surface of the soil pressure boxes must face to the measured soil. Meanwhile, the following issues require attention, including that the soil surface under soil pressure boxes must be strictly levelled, the material of backfill soil should be the same with the surrounding soil (stone removed), and artificial compaction in layers must be used carefully. The frequency was sensed by a frequency meter. No test result was obtained from section K63 +076 because of the damage of soil pressure boxes due to abutment excavation.

Variations of the pile-soil stress ratio $n_{s}$ and shared load ratio $N$ are shown in Figure 18. During embankment construction and preloading period, $n_{s}$ and $N$ increased at first and then decreased. In the early filling period (the first 24 days), when the cumulative filling height was $1.2 \mathrm{~m}$, the pile-soil pressure ratio $n_{s}$ rose from 1.6 to 2.9 and the shared load ratio $N$ rose from 0.09 to 0.16 , slowly. From day 25 to day 100 , the filling height grew from $1.2 \mathrm{~m}$ to $4.2 \mathrm{~m}$, the pilesoil pressure ratio rose from 2.9 to 16.8 , and the shared load ratio rose from 0.16 to 0.92 . On day 100 , after the cumulative filling height reaching $4.2 \mathrm{~m}$, the pile-soil pressure ratio and the shared load ratio reached the maximum values 16.8 and 0.92 , respectively. From day 100 to day 120, the filling height rose from $4.2 \mathrm{~m}$ to $7.9 \mathrm{~m}$, the pile-soil ratio reduced from 16.8 to 13.2 , and the shared load ratio reduced from 0.92 to 0.72 . From finishing preloading (day 100) to observation being over (day 150), the pile-soil pressure ratio rose from 13.2 to 15 , and the shared load ratio rose from 0.72 to 0.82 , indicating that the pile-soil pressure ratio and the shared load ratio still rose gradually after dead load, the load carried by the pile soil transferred to the pile top, and the effect of reinforcement on the composite foundation strengthened continually. 


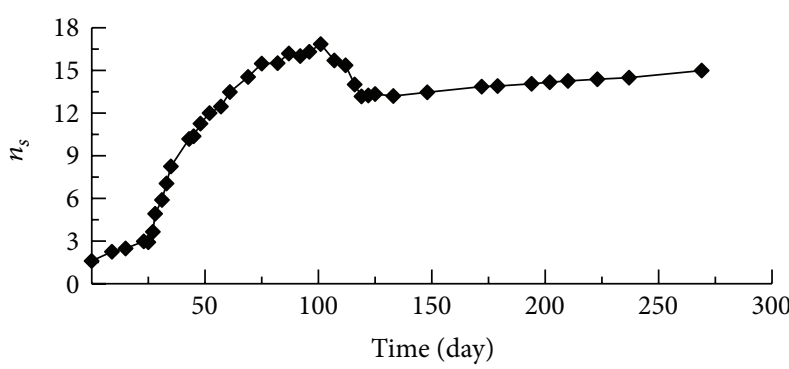

(a)

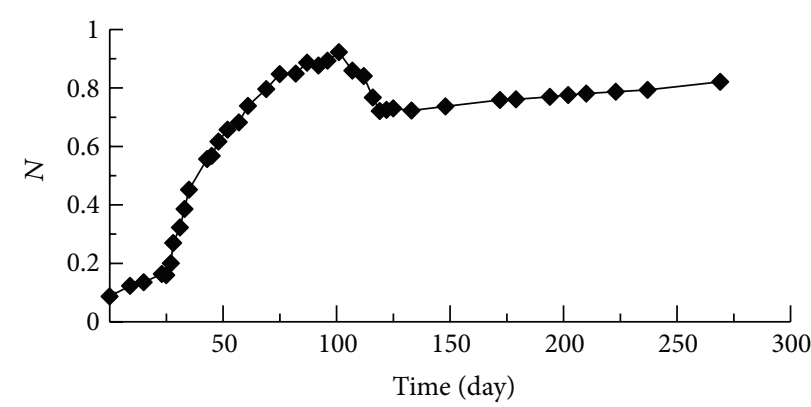

(b)

FIGURE 18: Variation of pile-soil stress ratio $n_{s}$ and shared load ratio $N$.

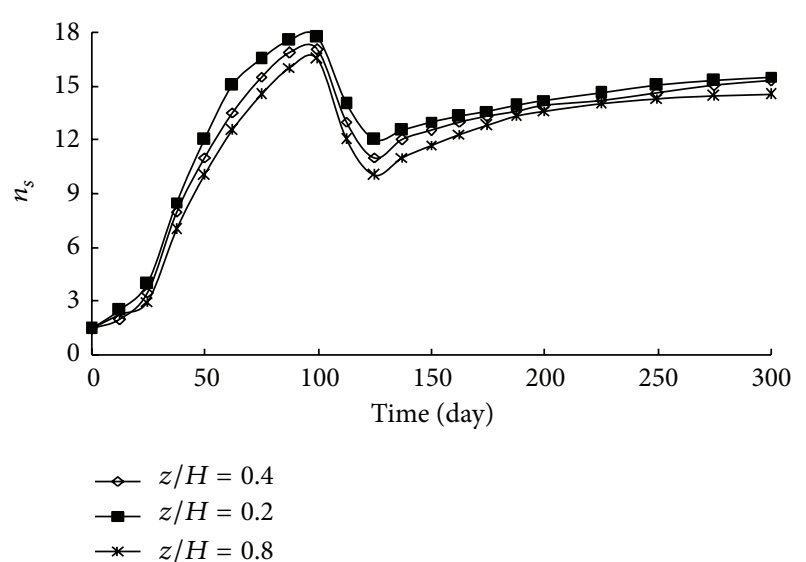

FIGURE 19: Variation of pile-soil stress ratio $n_{s}$ obtained by theoretical equation.

Figure 19 shows the variation of pile-soil stress ratio $n_{s}$ obtained by the amended equation, which is similar to Figure 18. It can be seen that the value of $n_{s}$ varied in different depth and increased when approaching to the surface. It means that the pile shared greater stress and the soil undertakes smaller load at the smaller depth place.

\section{Conclusions}

The general solution for consolidation of CCSG pile composite foundation under equal strain hypothesis was obtained by considering the variation of horizontal penetration parameter in influence zone, radial flow within the sand-gravel shell, and the impervious characteristic of concrete-cored pile in this paper. Meanwhile, this paper also introduced a series of field tests on CCSG pile composite foundation to prove the correctness of the general solution, including the settlement of pile and soil, the pore water pressure, and the soil pressure under embankment load. It is concluded that the new style composite foundation patent technology has many advantages such as small post-construction and differential post-construction settlement, reliable quality, high bearing capacity, high speed of settlement, and stability. The following main conclusions are obtained.
(1) The solution given by Terzaghi is a limited case of the present solution when $a=0, X=1, Y=1$, $k_{v}=k_{v w}$, and $k_{h}=k_{h w}$; the solution for ordinary granular material pile composite foundation is also a limited case of the present solution when $a=0$ and $X=1$. The consolidation rate of CCSG pile composite foundation is greater than that of natural foundation, sand drained ground, and ordinary granular material pile composite foundation.

(2) A parametric study shows that an increase in the values of $a, X$, and $Y$ and a decrease in the values of $n$, $s$, and $H / d_{w}$ will accelerate the consolidation rate of CCSG pile composite foundation.

(3) The analytical solution in this paper was finally validated with the actual filed measurement data.

(4) The essence of the composite foundation soil is that the reinforcement and subgrade soil mass undertake the load from the upper structure. To improve the bearing capacity of the foundation soil in thick and soft ground area, the area replacement ratio of piles can be appropriately improved with the project cost, and the pile length or the bearing capacity of soft soil can be increased. Meanwhile, the existence of the granular columns and the critical pile length in rigidflexible piles made the increased pile length difficult to play a full role. Compared with the rigid pile, the concrete-cored sand-gravel pile makes full use of the concrete-cored sand gravel shell capacity of drainage and consolidation to increase the bearing capacity of the soft soil.

(5) The total settlement of subgrade of CCSG pile composite foundation during embankment construction and preloading periods is bigger than that of churning pile and other composite foundations. The reason is that the concrete-cored sand gravel shell provides large diameter vertical drainage channel and reduces the drainage distance of the soil mass greatly, so the subsoil can produce larger consolidation settlement in a short time. Excess pore-pressure can dissipate in a short time, so the subgrade settlement is faster and becomes stable quickly. Four months after the precompression at the experimental section, the settlement rate was $5 \mathrm{~mm}$ per month, which indicated that 
the settlement becames stable, the precompression time fits in with that of the common sand drain.

Experimental results illustrate that adopting the concretecored sand-gravel pile composite foundation for thick and soft ground treatment at bridge head and the controlling of post-construction settlement is feasible. The test results also verify the advance, rationality, and validity of CCSG pile composite foundation. Because of the effect of soft soil consolidation and composite foundation that take place at the same time, the soil and the composite foundation interact and the relative displacement and interaction relationship among concrete-cored pile, soil, and sand-gravel shell are very complicated. So the deformation and load characteristics, especially the reinforcement mechanism under soft load, remain to be further studied.

\section{Acknowledgments}

This research was supported by the National Nature Foundation of China (Grant nos. 51374112, 51308234 and 51208321) and Natural Science Foundation of Fujian Province (no. 2013J05079); all support is gratefully acknowledged.

\section{References}

[1] R. A. Barron, "Consolidation of fine-grained soils by drain wells," Transactions of the American Society of Civil Engineers, vol. 113, no. 2346, pp. 718-742, 1948.

[2] R. R. Goughnour and A. A. Bayuk, "Analysis of stone column soil matrix interaction under vertical load," in Proceedings of International Conference on Soil Reinforcement, pp. 279-285, Paris, France, 1979.

[3] X. W. Tang and K. Onitsuka, "Consolidation of ground with partially penetrated vertical drains," Geotechnical Engineering, vol. 29, no. 2, pp. 209-227, 1998.

[4] K. H. Xie, "Present situation and development of consolidation theory of composite ground," Ground Improvement, vol. 4, no. 3, pp. 1-14, 1993.

[5] K. H. Xie, Sand drained ground: analytical \& numerical solutions of consolidation and optimum design [Ph.D. dissertation], Zhejiang University, Hangzhou, China, 1987.

[6] C. J. Leo, "Equal strain consolidation by vertical drains," Journal of Geotechnical and Geoenvironmental Engineering, vol. 130, no. 3, pp. 316-327, 2004.

[7] G. H. Lei, C. X. Jiang, and C. J. leo, "Discussion of "Equal strain consolidation by vertical drains" by Chin Jian Leo," Journal of Geotechnical and Geoenvironmental Engineering, vol. 131, no. 10, pp. 1315-1317, 2005.

[8] G. Zhu and J. H. Yin, "Consolidation of soil with vertical and horizontal drainage under ramp load," Geotechnique, vol. 51, no. 4, pp. 361-367, 2001.

[9] G. Zhu and J. H. Yin, "Consolidation analysis of soil with vertical and horizontal drainage under ramp loading considering smear effects," Geotextiles and Geomembranes, vol. 22, no. 1-2, pp. 63-74, 2004.

[10] X. S. Wang and J. J. Jiao, "Analysis of soil consolidation by vertical drains with double porosity model," International Journal for Numerical and Analytical Methods in Geomechanics, vol. 28, no. 14, pp. 1385-1400, 2004.
[11] R. Walker and B. Indraratna, "Vertical drain consolidation with parabolic distribution of permeability in smear zone," Journal of Geotechnical and Geoenvironmental Engineering, vol. 132, no. 7, pp. 937-941, 2006.

[12] B. Indraratna, C. Rujikiatkamjorn, and L. Sathananthan, "Radial consolidation of clay using compressibility indices and varying horizontal permeability," Canadian Geotechnical Journal, vol. 42, no. 5, pp. 1330-1341, 2005.

[13] D. Basu and M. Prezzi, "Effect of the smear and transition zones around prefabricated vertical drains installed in a triangular pattern on the rate of soil consolidation," International Journal of Geomechanics, vol. 7, no. 1, pp. 34-43, 2007.

[14] J. Castro and C. Sagaseta, "Consolidation around stone columns. Influence of column deformation," International Journal for Numerical and Analytical Methods in Geomechanics, vol. 33, no. 7, pp. 851-877, 2009.

[15] K. H. Xie, M. M. Lu, A. F. Hu, and G. H. Chen, "A general theoretical solution for the consolidation of a composite foundation," Computers and Geotechnics, vol. 36, no. 1-2, pp. 24-30, 2009.

[16] K. H. Xiel, M. M. Lu, and G. B. Liu, "Equal strain consolidation for stone columns reinforced foundation," International Journal for Numerical and Analytical Methods in Geomechanics, vol. 33, no. 15, pp. 1721-1735, 2009.

[17] J. C. Chai and N. Miura, "Investigation of factors affecting vertical drain behaviour," Journal of Geotechnical and Geoenvironmental Engineering, vol. 125, no. 3, pp. 216-226, 1999.

[18] J. S. Sharma and D. Xiao, "Characterization of a smear zone around vertical drains by large-scale laboratory tests," Canadian Geotechnical Journal, vol. 37, no. 6, pp. 1265-1271, 2000.

[19] B. C. Hawlader, G. Imai, and B. Muhunthan, "Numerical study of the factors affecting the consolidation of clay with vertical drains," Geotextiles and Geomembranes, vol. 20, no. 4, pp. 213239, 2002.

[20] B. Indraratna and I. W. Redana, "Laboratory determination of smear zone due to vertical drain installation," Journal of Geotechnical and Geoenvironmental Engineering, vol. 124, no. 2, pp. 180-184, 1998.

[21] A. Onoue, N. H. Ting, J. T. Germaine, and R. V. Whitman, "Permeability of disturbed zone around vertical drains," in Proceedings of the Geotechnical Engineering Congress, pp. 879890, Boulder, Colo, USA, 1991.

[22] R. Walker and B. Indraratna, "Vertical drain consolidation with overlapping smear zones," Geotechnique, vol. 57, no. 5, pp. 463467, 2007.

[23] X. W. Tang and K. Onitsuka, "Consolidation by vertical drains under time-dependent loading," International Journal for Numerical and Analytical Methods in Geomechanics, vol. 24, no. 9, pp. 739-751, 2000.

[24] Y. G. Zhang, K. H. Xie, and Z. Wang, "Consolidation analysis of composite ground improved by granular columns considering variation of permeability coefficient of soil," in Ground Modification and Seismic Mitigation, GSP 152, 2006.

[25] M. M. Lu, K. H. Xie, and B. Guo, "Consolidation theory for a composite foundation considering radial and vertical flows within the column and the variation of soil permeability within the disturbed soil zone," Canadian Geotechnical Journal, vol. 47, no. 2, pp. 207-217, 2010.

[26] M. M. Lu, K. H. Xie, A. F. Hu, and G. H. Chen, "Reply to Comments on "A general theoretical solution for the consolidation of a composite foundation" [Computers and Geotechnics 36 
(2009) 24-30]," Computers and Geotechnics, vol. 37, no. 4, pp. 582-583, 2010.

[27] M. M. Lu, K. H. Xie, C. X. Li, and K. Wang, "Consolidation solution for composite foundation considering a time- and depth-dependent stress increment along with three distribution patterns of soil permeability, Journal of Zhejiang University: Science A, vol. 12, no. 4, pp. 268-277, 2011.

[28] M. M. Lu, K. H. Xie, and S. Y. Wang, "Consolidation of vertical drain with depth-varying stress induced by multi-stage loading," Computers and Geotechnics, vol. 38, no. 8, pp. 10961101, 2011.

[29] R. C. Wang, K. H. Xie, and S. H. Guan, "Analytical solutions for consolidation of composite ground with granular columns under timedependent loading," Journal of Zhejiang University, vol. 36, no. 1, pp. 12-16, 2002.

[30] M. M. Lu, K. H. Xie, S. Y. Wang, and C. X. Li, "Analytical solution for the consolidation of a composite foundation reinforced by impervious column with an arbitrary stress increment," ASCE International Journal of Geomechanics, vol. 13, no. 1, pp. 33-40, 2013. 


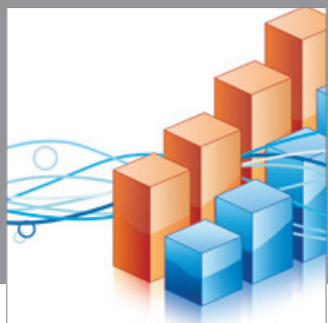

Advances in

Operations Research

mansans

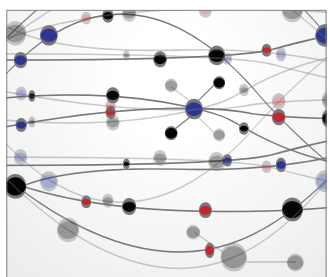

The Scientific World Journal
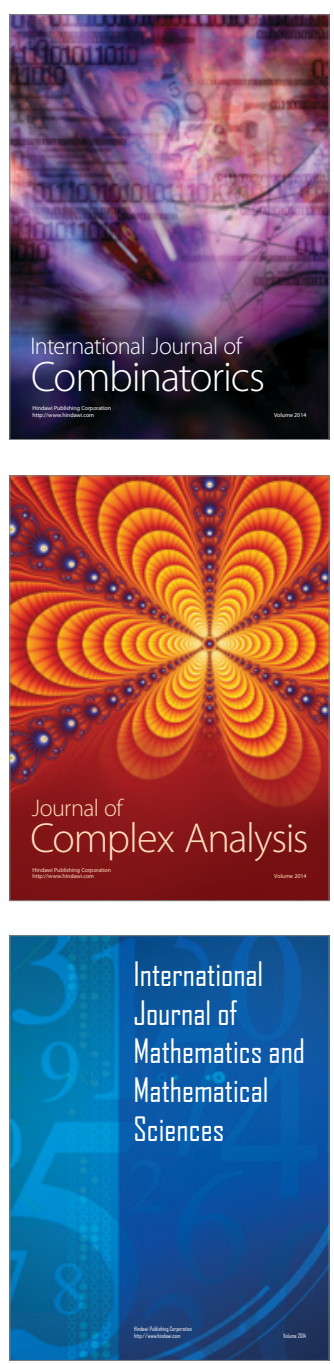
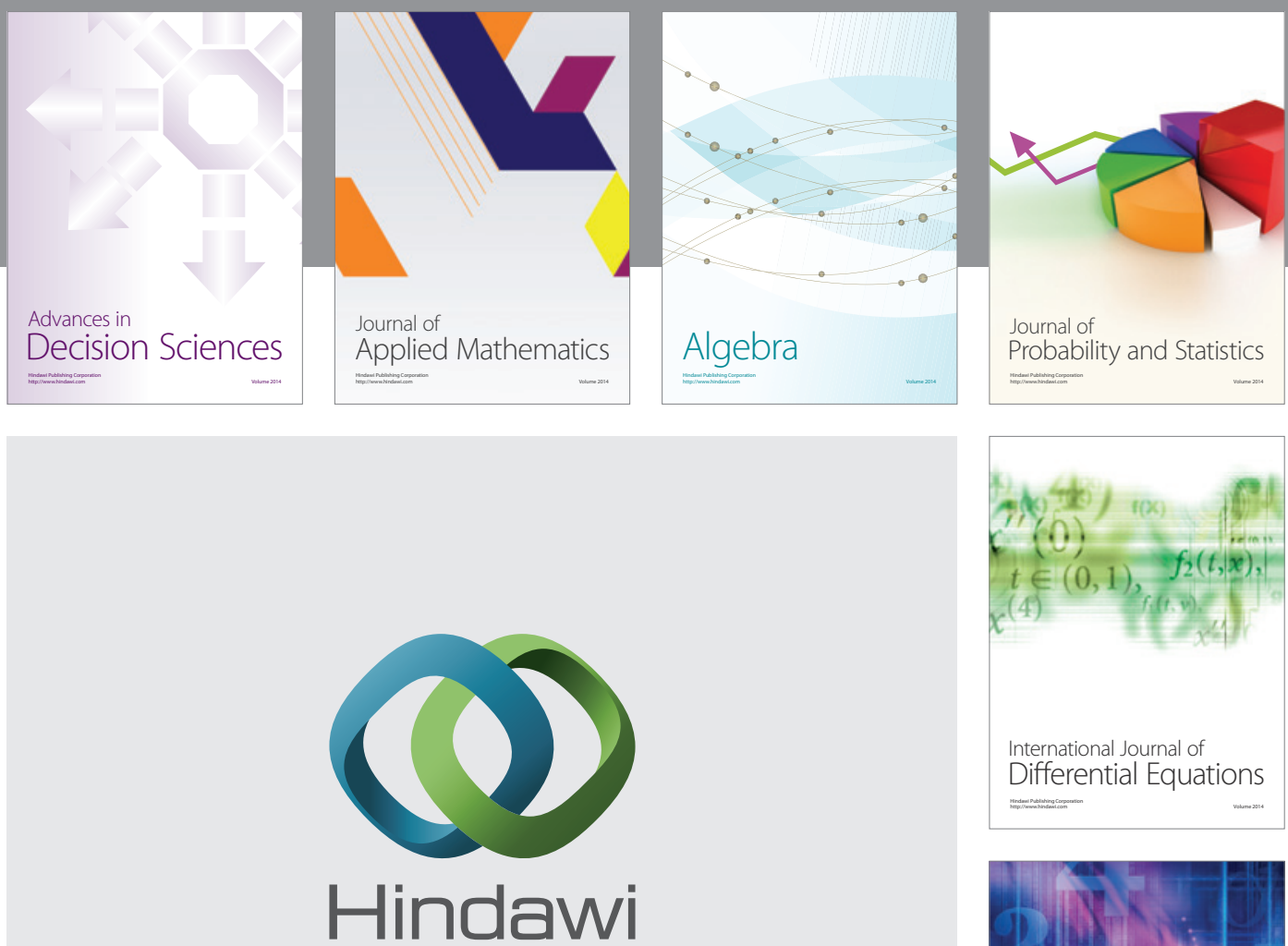

Submit your manuscripts at http://www.hindawi.com
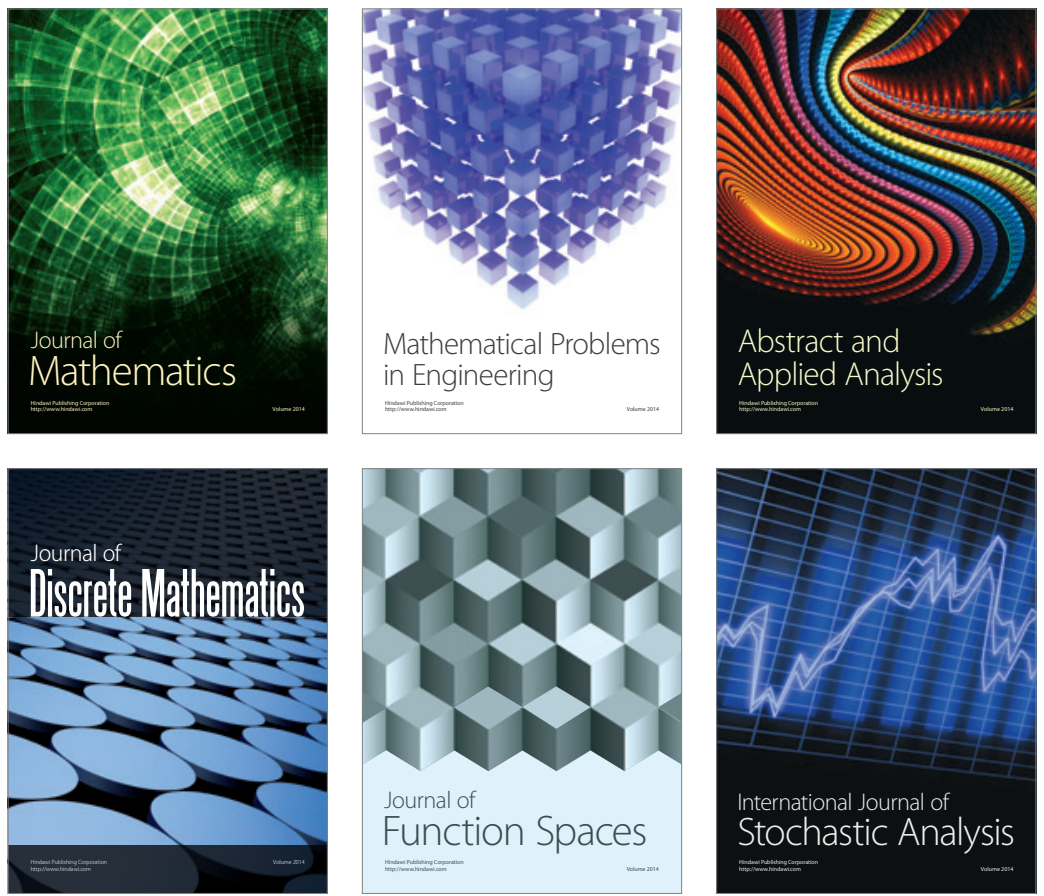

Journal of

Function Spaces

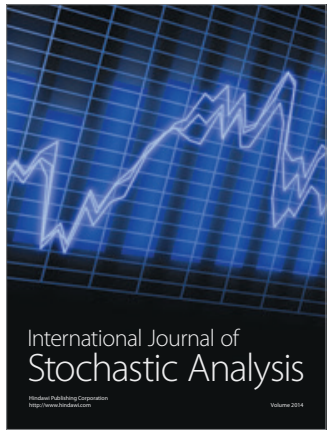

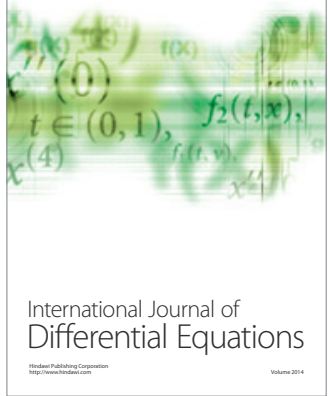
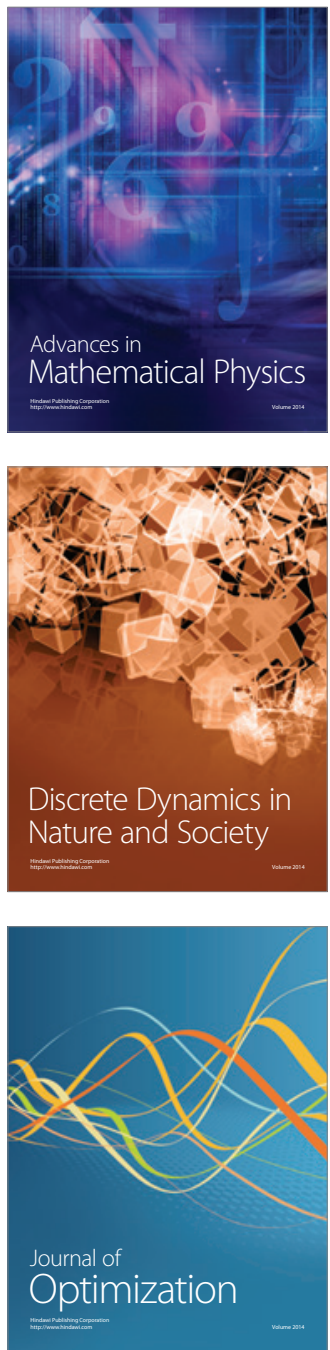